\title{
Investigation of a novel method for improving hemodynamics of Fontan circuit using an experimental model
}

\author{
Suneet Bhansali ${ }^{1}$, Tsusheel Kumar ${ }^{1}$, Maya Crawford Crawford ${ }^{2}$, and Nikhil R. Katre ${ }^{3}$ \\ ${ }^{1}$ NYU Langone Health \\ ${ }^{2}$ Northeastern University Department of Biology \\ ${ }^{3}$ Veol Medical Technologies Pvt Ltd Navi Mumbai India
}

November 11, 2021

\begin{abstract}
Background: The study objective was to test underlying physical laws behind a proposed novel device for failing Fontan and investigate whether the device could be implemented theoretically to improve hemodynamics in failing Fontan circulation. Methods: A 4-arm setup was designed and fabricated to simulate an actual Fontan circuit in the form of a junction of the superior and inferior vena cavae (SVC, IVC) with the right and left pulmonary arteries (RPA, LPA). A provision for placement of an oscillating ball along the RPA-LPA path to push fluid away from SVC and IVC was created. The rate of ball oscillations and initial pressure of fluid on SVC and IVC limbs were varied. The pressure-drop times in the vena cavae limbs were measured at varying ball oscillations and resistances in the RPA-LPA pathway. The test was considered positive if increasing oscillations of the ball allowed for quicker pressure drop in the SVC and IVC limbs indicating quicker discharge of fluid through the RPA and LPA. 48 different experiments were conducted to simulate different physical conditions and the results were plotted and analyzed to draw a conclusion. Results: The time required for pressure drop in the experiment without ball was the least across all set of readings. This meant that placing an oscillating ball along the RPA -LPA path created obstruction to flow rather than enhance it. Increasing rate of ball oscillations increased degree of obstruction to flow. Conclusion: The proposed interventional method is unsuitable for improving hemodynamics in failing Fontan circulation.
\end{abstract}

Title: Investigation of a novel method for improving hemodynamics of Fontan circuit using an experimental model

Authors: T.K. Susheel Kumar, MD ${ }^{1}$, Suneet Bhansali, $\mathrm{MD}^{2}$, Maya T Crawford ${ }^{3}$, Nikhil R Katre, $\mathrm{Mdes}^{4}$

Affiliations:

${ }^{1}$ Department of Congenital Cardiothoracic Surgery, NYU Langone Health, New York, USA,

${ }^{2}$ Department of Pediatric Cardiology, NYU Langone Health, New York, USA

${ }^{3}$ Department of Biology, Northeastern University, Boston, USA

${ }^{4}$ Veol Medical Technologies Pvt. Ltd., Navi Mumbai, India

\section{Corresponding author :}

TK Susheel Kumar, MD

Associate Professor, Department of Congenital Cardiothoracic Surgery,

NYU Langone Health,

New York, NY 10016 
Email: tksusheel.kumar@nyulangone.org

Phone: 212-263-1370

Fax: 212-263-0437

Key words : Fontan, complications, device, hemodynamics, oscillating ball

Accepted for oral presentation at 16th International Conference on Pediatric Mechanical Circulatory Support Systems 83 Pediatric Cardiopulmonary Perfusion on May 14-15, 2020 (Meeting Cancelled due to COVID-19 Pandemic).

IRB Approval, consent, and clinical trial registration are not applicable for this study. No patient data was accessed for the completion of this study and manuscript.

Main document word count : 1861

Abstract Word Count: 250

Statement of financial support : No institutional or private financial support was received for this study.

Conflict of interest : No potential conflict exists for any of the authors

\section{Summary of author contributions}

Dr.TK Susheel Kumar contributed to the concept, design, data analysis, drafting of the article and critical revision of the article

Dr. Suneet Bhansali contributed to the concept, data analysis, drafting of the article and critical revision of the article.

Maya Crawford contributed to the concept, data analysis, drafting of the article and critical revision of the article.

Nikhil R. Katre contributed to the concept, design, data collection, data analysis, statistics and drafting of the article.

\section{Abstract}

Background: The study objective was to test underlying physical laws behind a proposed novel device for failing Fontan and investigate whether the device could be implemented theoretically to improve hemodynamics in failing Fontan circulation.

Methods : A 4-arm setup was designed and fabricated to simulate an actual Fontan circuit in the form of a junction of the superior and inferior vena cavae (SVC, IVC) with the right and left pulmonary arteries (RPA, LPA). A provision for placement of an oscillating ball along the RPA-LPA path to push fluid away from SVC and IVC was created. The rate of ball oscillations and initial pressure of fluid on SVC and IVC limbs were varied. The pressure-drop times in the vena cavae limbs were measured at varying ball oscillations and resistances in the RPA-LPA pathway. The test was considered positive if increasing oscillations of the ball allowed for quicker pressure drop in the SVC and IVC limbs indicating quicker discharge of fluid through the RPA and LPA. 48 different experiments were conducted to simulate different physical conditions and the results were plotted and analyzed to draw a conclusion.

Results : The time required for pressure drop in the experiment without ball was the least across all set of readings. This meant that placing an oscillating ball along the RPA -LPA path created obstruction to flow rather than enhance it. Increasing rate of ball oscillations increased degree of obstruction to flow.

Conclusion : The proposed interventional method is unsuitable for improving hemodynamics in failing Fontan circulation.

\section{Abbreviations}


RPA: right pulmonary artery

LPA: left pulmonary artery

$\mathrm{RV}$ : right ventricle

IVC: inferior vena cava

SVC: superior vena cava

\section{Introduction}

Approximately 50 years ago, Francis Fontan pioneered an operation for tricuspid atresia that bears his name today. ${ }^{1}$ The Fontan procedure refers to any operation that shunts the systemic venous return to the pulmonary bed by bypassing the right ventricle (RV) or the subpulmonary ventricle. It can be applied to a wide array of congenital heart diseases such as tricuspid atresia, hypoplastic left heart syndrome and unbalanced atrioventricular canal where there is a single functional ventricle. Despite restoring normal oxygen levels in the body, the operation creates a neoportal system where adequate cardiac output can be generated only at the expense of increased systemic venous congestion. ${ }^{2}$ Additionally, the loss of pulsatility and chronic low-flow state of Fontan circulation induces pulmonary vasoconstriction and raises the pulmonary vascular resistance. This results in slow but relentless damage to the end organ systems, especially the liver. Numerous designs of assist devices that have been previously described provide a push to the venous blood entering the lungs to mimic a normal RV. ${ }^{3-5}$ A novel interventional approach in the form of an oscillating ball along the pulmonary artery pathway to improve the hemodynamics in failing Fontan circuit is studied herewith. The objective of the experimental study was to test the hypothesis that placement of an oscillating ball along the pulmonary artery pathway in an experimental Fontan model would increase the forward flow of blood into the lungs and reduce the pressure in the systemic veins.

\section{Materials and methods}

An experimental model to mimic the Fontan circuit was created. The crux of the model was the creation of a junction between the branch pulmonary arteries and the vena cavae. The approximate dimensions of relevant blood vessels in an average adult Fontan patient such as superior vena cava (SVC), inferior vena cava (IVC), right pulmonary artery (RPA) and left pulmonary artery (LPA) were used as reference (see Table 1). A 4-arm setup to mimic these dimensions as far as practically possible was designed and fabricated using acrylic pipes and a specially made junction. Table 1 describes the dimensions of the vessels in the human body and the dimensions provided in the simulated setup. There was some limitation in mimicking the actual anatomical dimensions in the simulated setup because we used standard available components in the setup.

A mechanical arrangement was designed and fabricated to enable placement of a ball inside the 4-arm setup along the RPA-LPA pathway. Furthermore, a driving mechanism was also fabricated to mechanically oscillate the ball along the LPA-RPA pathway. (Figure 1)(Video 1) The dimension of the ball selected was $18 \mathrm{~mm}$ such that it could move easily along the RPA-LPA pathway without completely occluding it and allow fluid to pass around the ball. The reason for keeping some gap between the ball and the pathway was to avoid total dependence of the movement of the blood and hemodynamics only on the motion of the ball. In case the ball failed, blood would be still able to flow around the ball thereby providing a safety mechanism.

Two fluid inlet reservoirs, one each was attached to the top of the SVC and IVC limbs (Figures 2 and 3). The reservoirs were made of sufficient height so that a pressure head of fluid equivalent to the actual venous pressure in the venous side of the Fontan circuit could be created by filling fluid into the reservoirs. We used two different fluids in the setup; one was water and another was a mixture of water and glycerine to simulate the viscosity of blood. Typical pressures in the SVC and IVC along with the corresponding height of fluid column in the fluid inlet reservoirs are mentioned in Table 2. We conducted experiments at two levels of venous pressure head equivalent to $20 \mathrm{mmHg}$ and $10 \mathrm{mmHg}$ pressure to mimic a high and low venous pressure Fontan system. 
Two fluid outlet reservoirs, one each was placed below the RPA and LPA to collect the fluid coming out. Stopcocks were placed one each at the end of RPA and LPA limbs to control the flow of the fluid out of RPA and LPA. The purpose of the stopcocks was to simulate various levels of resistance to flow as encountered in patients with failing Fontan circuit. We conducted experiments with three levels of resistance; 30 degree opening of the stopcock indicating high resistance to flow, 60 degree indicating low resistance and 90 degree indicating no resistance (free-flow) condition.

The oscillating ball was intended to act as a pump to increase the rate of fluid output coming out from the RPA and LPA. We used three speeds of oscillation; 40 strokes $/ \mathrm{min}, 72$ strokes/min and 100 strokes/min to test the hypothesis. A condition without the ball was also tested as a baseline. In order to simulate the viscosity of blood, a mixture consisting of $52 \%$ Glycerin and $48 \%$ water by volume was made. ${ }^{6}$ This blood analog was used as one of the fluids in the setup.

\section{Experiments}

We conducted two sets of experiments with the 4-arm setup. Set A of experiments involved allowing the fluid pressure in the inlet reservoirs to drop from predetermined level to zero and measuring the time required to achieve this pressure drop (Videos 2 and 3). A total of 48 different experiments were conducted under set A for various conditions as shown in Table 3. In general, shorter time required to achieve pressure drop indicates better drainage of fluid through the RPA-LPA pathway.

Set B of experiments involved maintaining the fluid pressure in the inlet reservoirs constant by replenishing the fluid continuously. The time required for flow of 1 liter of fluid each out of LPA and RPA at constant pressure was recorded. A total of 12 different experiments were conducted under set B for conditions as shown in Table 4. In general, less time required for flow of set volume of fluid (a total of 2 liters) indicates better drainage of fluid through RPA-LPA pathway.

\section{Results}

The readings for the set A experiments are shown in Figure 4 and Figure 5. It was noted across all the experiments in set $\mathrm{A}$, the time required for achieving pressure drop was the least when no ball was present in the setup (which is free flow condition).

The readings for the set B experiments are shown in Figure 6. In set B, it was noticed that the time required for a flow of 2 liters of fluid at a constant pressure through the setup was least when there was no ball in the setup.

Inference

The hypothesis behind conducting these experiments was that placement of an oscillating ball would decrease the venous congestion and increase the flow through the lungs in patients with failing Fontan circuit. The experiments have proved that an oscillating ball does not help in clearing the congestion, on the contrary, it may act as a hindrance to flow.

\section{Discussion}

In the early 1970s, Francis Fontan and Kreutzer independently used the concept of the 'dispensable RV' to design a new circulation that had not previously been witnessed in evolution. ${ }^{1,7}$ The 'Fontan operation' as it popularly became known as launched the era of surgical treatment of functionally univentricular hearts. The Fontan operation itself has also undergone numerous modifications in the last few decades with the extracardiac Fontan operation being the most widely used design today. ${ }^{8}$ Although the Fontan operation can be performed with very low mortality today, the morbidity associated with this unique circulation has become an ever increasing problem. ${ }^{9}$ Early on, Dr. Francis Fontan himself predicted the significant attrition associated with the new operation over time. ${ }^{10}$ The entire problem of the Fontan operation is related to the lack of the final push to the venous blood before it enters the lungs. The Fontan operation essentially creates a neo portal system where adequate LV loading can happen only at the expense of raised central venous pressure. ${ }^{2}$ Moreover, in the absence of a sub-pulmonary pump any small changes in the resistance of 
this neo-portal system can lead to significant alterations in cardiac output. The bottle neck of the cardiac output is the resistance offered by this neo-portal system rather than the pumping mechanism of the heart itself although in the final stages this too may be affected and worsens the Fontan circulation all the more. The term 'Fontan failure' is a loosely applied term with some authors using it solely for exercise intolerance, while others reserve it for late stages of overt failure such as ascites, protein losing enteropathy and plastic bronchitis. Perfusion of the liver is particularly endangered following Fontan operation. Decreased portal blood flow coupled with chronic elevation in pulmonary capillary bed pressure ultimately results in fibrosis progressing to cirrhosis in many patients with Fontan circulation. ${ }^{11}$

Traditional heart failure therapy may not be as effective as medications that can lower the resistance of the Fontan neo portal system. ${ }^{12}$ Percutaneous creation of fenestration is also not very effective as an intervention for failing Fontan patients. Achieving a good balance between cyanosis, decreased congestion and improved cardiac output can be challenging. ${ }^{13}$ Fontan failure can sometimes be a consequence of structural issues that may be amenable to surgical correction. Conversion of the atriopulmonary connection to cavopulmonary connection using lateral tunnel technique or extracardiac type of Fontan procedure reduces not only the energy loss but also the transcoronary pressure gradient by placement of the coronary sinus on the pulmonary venous side of the circulation. ${ }^{14}$ Heart transplantation can provide effective therapy for end stage Fontan failure. However, outcomes of heart transplantation for the failing Fontan patient are not as favorable as for other congenital heart diseases. ${ }^{15}$ The continued shortage of donor organs with an ever increasing population of Fontan patients and suboptimal outcomes of heart transplantation have propelled the need for an effective mechanical circulatory support device not only as a bridge to transplantation but also as a destination device. Many patients with failing Fontan physiology have preserved systemic ventricular function and hence application of a systemic ventricular assist device is unlikely to be effective. For such patients a right sided subpulmonary ventricular assist device may afford a better solution. A variety of novel Fontan specific devices have been proposed each with its own limitations (Table 5).$^{3-5}$ Our study was an attempt towards the same end. The purpose of this study was to test whether the idea of an oscillating ball would work in the Fontan circuit. The mechanism seemed simple and theoretically attractive. The device, if successful could be potentially implemented in most adult Fontan patients as an oscillating ball placed in a stent in the branch pulmonary arteries within the existing Fontan configuration. Unfortunately, as our own studies in the lab proved, the results were counter intuitive. Perhaps, testing the concept within a closed circuit or using computational flow dynamics may have yielded different results. We hope our findings are useful for other groups making similar attempts to address the problem of Fontan failure.

\section{Conclusion :}

The proposed novel method for intervention is not a suitable option for improving hemodynamics in failing Fontan circulation. Other intervention modalities to improve hemodynamics remain to be explored.

\section{References:}

1. Fontan F, Baudet E. Surgical repair of tricuspid atresia. Thorax. 1971;26(3):240-8.

2. Gewillig M, Goldberg DJ. Failure of the fontan circulation. Heart Fail Clin. 2014;10(1):105-16.

3. Rodefeld MD, Coats B, Fisher T, et al. Cavopulmonary assist for the univentricular Fontan circulation: von Karman viscous impeller pump. J Thorac Cardiovasc Surg. 2010;140(3):529-36.

4. Lacour-Gayet FG, Lanning CJ, Stoica S, et al. An artificial right ventricle for failing fontan: in vitro and computational study. Ann Thorac Surg. 2009;88(1):170-6.

5. Pekkan K, Aka IB, Tutsak E, et al. In vitro validation of a self-driving aortic-turbine venous-assist device for Fontan patients. J Thorac Cardiovasc Surg. 2018;156(1):292-301 e7.

6. Chung J, Lee JJ, Choi J, Kim J, Min BG. Hydrodynamic and static performance evaluation of the moving-actuator type biventricular assist device, AnyHeart. ASAIO J. 2003;49(5):599-603. 
7. Kreutzer G, Galindez E, Bono H, De Palma C, Laura JP. An operation for the correction of tricuspid atresia. J Thorac Cardiovasc Surg. 1973;66(4):613-21.

8. Giannico S, Hammad F, Amodeo A, et al. Clinical outcome of 193 extracardiac Fontan patients: the first 15 years. J Am Coll Cardiol. 2006;47(10):2065-73.

9. Tokunaga S, Kado H, Imoto Y, et al. Total cavopulmonary connection with an extracardiac conduit: experience with 100 patients. Ann Thorac Surg. 2002;73(1):76-80.

10. Fontan F, Kirklin JW, Fernandez G, et al. Outcome after a "perfect" Fontan operation. Circulation. 1990;81(5):1520-36.

11. Wu FM, Ukomadu C, Odze RD, Valente AM, Mayer JE, Jr., Earing MG. Liver disease in the patient with Fontan circulation. Congenit Heart Dis. 2011;6(3):190-201.

12. Ghanayem NS, Berger S, Tweddell JS. Medical management of the failing Fontan. Pediatr Cardiol. 2007;28(6):465-71.

13. Rupp S, Schieke C, Kerst G, et al. Creation of a transcatheter fenestration in children with failure of Fontan circulation: Focus on extracardiac conduit connection. Catheter Cardiovasc Interv. 2015;86(7):118994.

14. Huddleston CB. The failing Fontan: options for surgical therapy. Pediatr Cardiol. 2007;28(6):472-6.

15. Backer CL, Russell HM, Pahl E, et al. Heart transplantation for the failing Fontan. Ann Thorac Surg. 2013;96(4):1413-9.

\section{Tables}

\begin{tabular}{|c|c|c|c|}
\hline No. & Dimension & $\begin{array}{c}\text { Anatomical Value } \\
(\mathbf{m m})\end{array}$ & $\begin{array}{c}\text { Value in } \\
\text { experimental setup } \\
(\mathbf{m m})\end{array}$ \\
\hline 1 & Inner Diameter of Pulmonary Artery (LPA and RPA) & $20 / 20$ & $20 / 20$ \\
\hline 2 & Length of LPA & 50 & 40 \\
\hline 3 & Length of RPA & 15 & 40 \\
\hline 4 & Inner Diameter of Vena Cava (SVC and IVC) & $20 / 20$ & $15 / 15$ \\
\hline 5 & Length of SVC & 60 & 60 \\
\hline 6 & Length of IVC & 100 & 100 \\
\hline
\end{tabular}

Table 1. Dimensions of various components of mechanical set up. Anatomical values refer to average dimensions in an average sized Fontan patient.

\begin{tabular}{|c|c|c|c|}
\hline No. & $\begin{array}{c}\text { Pressure value } \\
\text { (mmHg) }\end{array}$ & $\begin{array}{c}\text { Equivalent level of } \\
\text { water } \\
\text { (mm) }\end{array}$ & $\begin{array}{c}\text { Equivalent level of } \\
\text { Water + Glycerin } \\
\text { (mm) }\end{array}$ \\
\hline 1 & 10 & 140 & 122 \\
\hline 2 & 20 & 280 & 245 \\
\hline
\end{tabular}

Table 2. Pressure and level of fluid used in experimental set up 
Table 3. Set A (pressure drop) experiments

\begin{tabular}{|c|c|c|c|c|c|}
\hline Sr. No. & Fluid medium & $\begin{array}{c}\text { Resistance to } \\
\text { flow }\end{array}$ & $\begin{array}{l}\text { Rate of ball } \\
\text { oscillation }\end{array}$ & $\begin{array}{l}\text { Pressure head on } \\
\text { LPA and RPA }\end{array}$ & \\
\hline 1 & Water & $\begin{array}{c}30 \text { deg. } \\
\text { (High Resistance) }\end{array}$ & 0 (No ball) & $20 \mathrm{mmHg}$ & \\
\hline 2 & $\begin{array}{c}\text { Glycerin+Water } \\
\text { (Simulated blood } \\
\text { viscosity) }\end{array}$ & $\begin{array}{c}60 \text { deg. } \\
\text { (Low Resistance) }\end{array}$ & 40 cycles/min & $10 \mathrm{mmHg}$ & \\
\hline 3 & & $\begin{array}{c}90 \text { deg. } \\
\text { (No resistance) }\end{array}$ & 72 cycles/min & & \\
\hline 4 & & & 100 cycles/min & & \\
\hline $\begin{array}{l}\text { No. of } \\
\text { variations }\end{array}$ & 2 & 3 & 4 & 2 & $\begin{array}{c}48 \\
\text { experiments }\end{array}$ \\
\hline
\end{tabular}

\begin{tabular}{|c|c|c|c|c|c|}
\hline Sr. No. & Fluid medium & $\begin{array}{l}\text { Resistance to } \\
\text { flow }\end{array}$ & $\begin{array}{l}\text { Rate of ball } \\
\text { oscillation }\end{array}$ & $\begin{array}{l}\text { Pressure head on } \\
\text { LPA and RPA }\end{array}$ & \\
\hline 1 & $\begin{array}{c}\text { Glycerin+Water } \\
\text { (Simulated blood } \\
\text { viscosity) }\end{array}$ & $\begin{array}{c}30 \text { deg. } \\
\text { (High Resistance) }\end{array}$ & 0 (No ball) & $20 \mathrm{mmHg}$ & \\
\hline 2 & & $\begin{array}{c}60 \text { deg. } \\
\text { (Low Resistance) }\end{array}$ & 40 cycles/min & & \\
\hline 3 & & $\begin{array}{l}90 \text { deg. } \\
\text { (No resistance) }\end{array}$ & 72 cycles/min & & \\
\hline 4 & & & 100 cycles/min & & \\
\hline $\begin{array}{l}\text { No. of } \\
\text { variations }\end{array}$ & 1 & 3 & 4 & 1 & $\begin{array}{c}12 \\
\text { experiments }\end{array}$ \\
\hline
\end{tabular}

Table 4. Set B (constant pressure) experiments

Table 5. Other attempts at cavopulmonary assist devices

\begin{tabular}{|c|c|c|}
\hline Author & Concept & Challenges \\
\hline Rodefeld et al (Reference 3) & $\begin{array}{l}\text { Viscous impeller pump based on } \\
\text { the Von Karman viscous pump } \\
\text { principle }\end{array}$ & $\begin{array}{l}\text { Design of expandable impeller } \\
\text { Need for reduced scale in children } \\
\text { Risk of hemolysis Risk of } \\
\text { thrombosis }\end{array}$ \\
\hline Lacour-Gayet et al (Reference 4) & $\begin{array}{l}\text { Low pressure axial flow pump } \\
\text { ('artificial RV') powered by } \\
\text { electricity to produce a } \\
\text { continuous low suction inflow } \\
\text { pressure on the venous side }\end{array}$ & $\begin{array}{l}\text { Requires reconfiguration of } \\
\text { existing Fontan circuit Requires } \\
\text { open heart surgery for } \\
\text { implantation Risk of hemolysis } \\
\text { Risk of thrombosis }\end{array}$ \\
\hline Pekkan et al (Reference 5) & $\begin{array}{l}\text { Implantable integrated aortic } \\
\text { turbine venous assist system } \\
\text { based on transfer of energy from } \\
\text { single ventricle outlet to the } \\
\text { venous side to reduce the venous } \\
\text { pressure }\end{array}$ & $\begin{array}{l}\text { Need for reduced scale in children } \\
\text { Risk of turbine flow pathway } \\
\text { blockage Risk of hemolysis Risk of } \\
\text { thrombosis }\end{array}$ \\
\hline
\end{tabular}

\section{Figure legends}

Figure 1. Schematic diagram of the Fontan experimental set up.

Figure 2. Photo of the actual set up. 
Figure 3. Computer model of actual set up.

Figure 4 showing set A pressure drop experiments with water.

Figure 5 showing set A pressure drop experiments with mixture of Glycerin and water (blood analog)

Figure 6 showing set B constant pressure experiments with mixture of Glycerin and water.

\section{Video legends (Supporting Information)}

Video 1. Working of the 4-arm setup

Video 2. Set A experiment with $140 \mathrm{~mm}$ water column, no resistance, ball oscillations at 40pm and experiment with $140 \mathrm{~mm}$ Water column, no resistance, no ball oscillations.

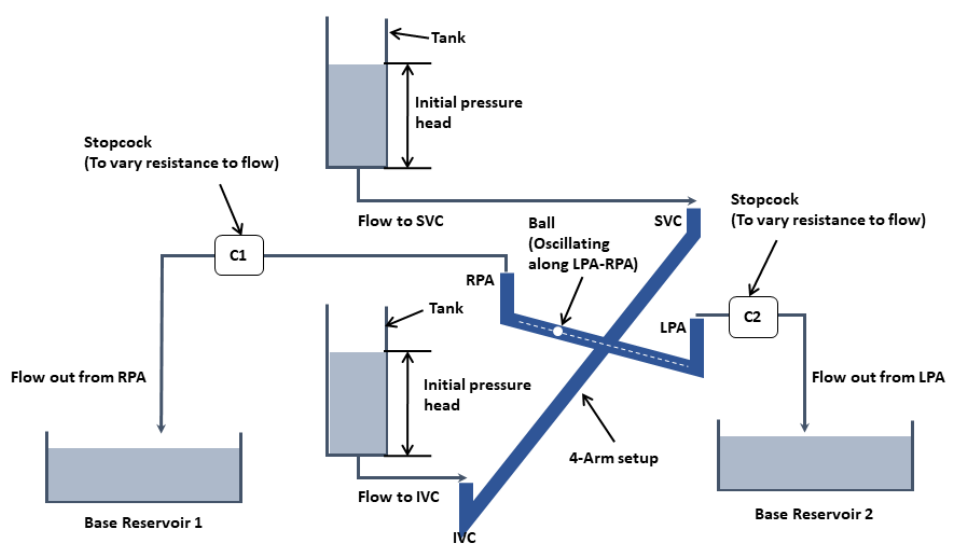



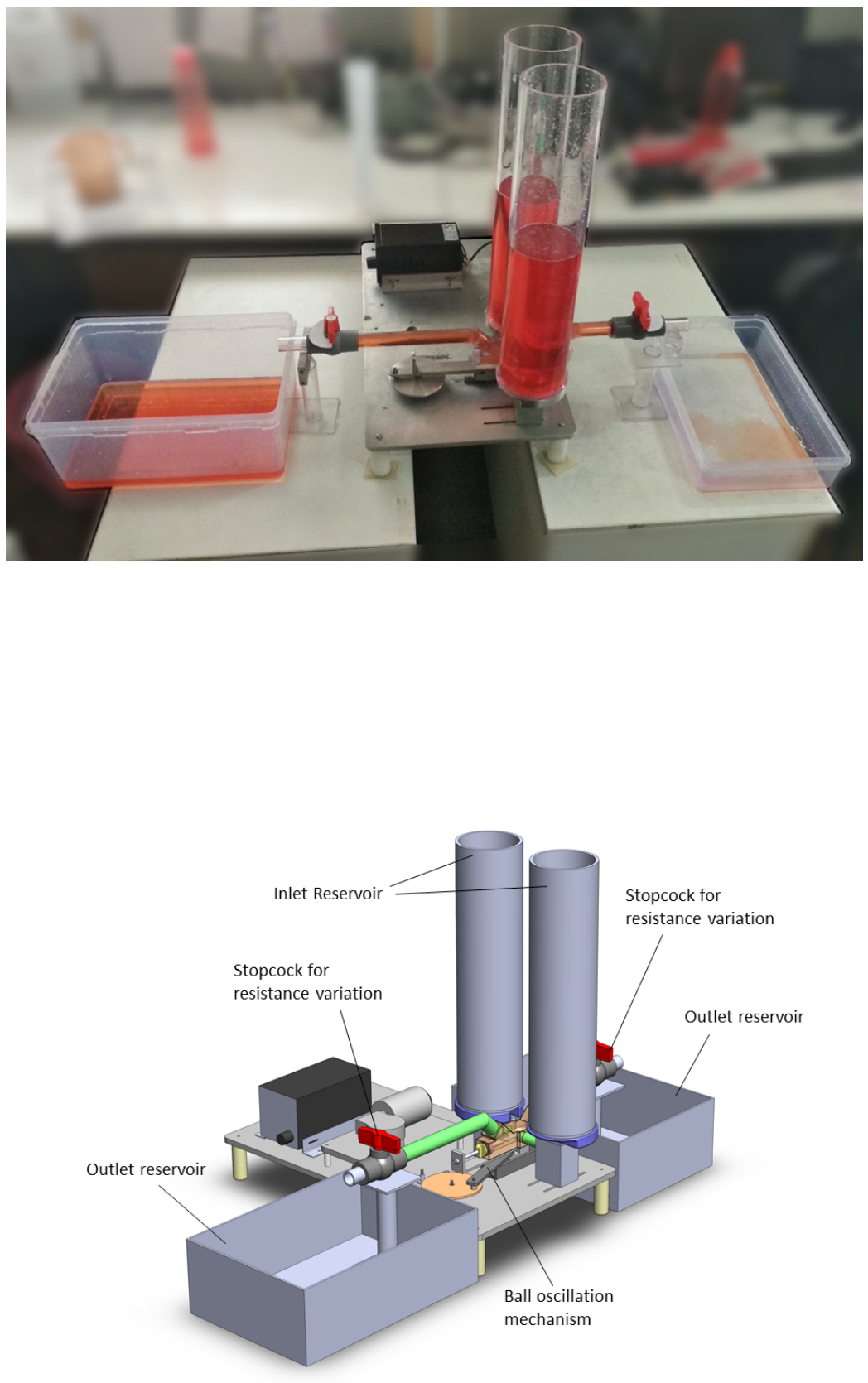

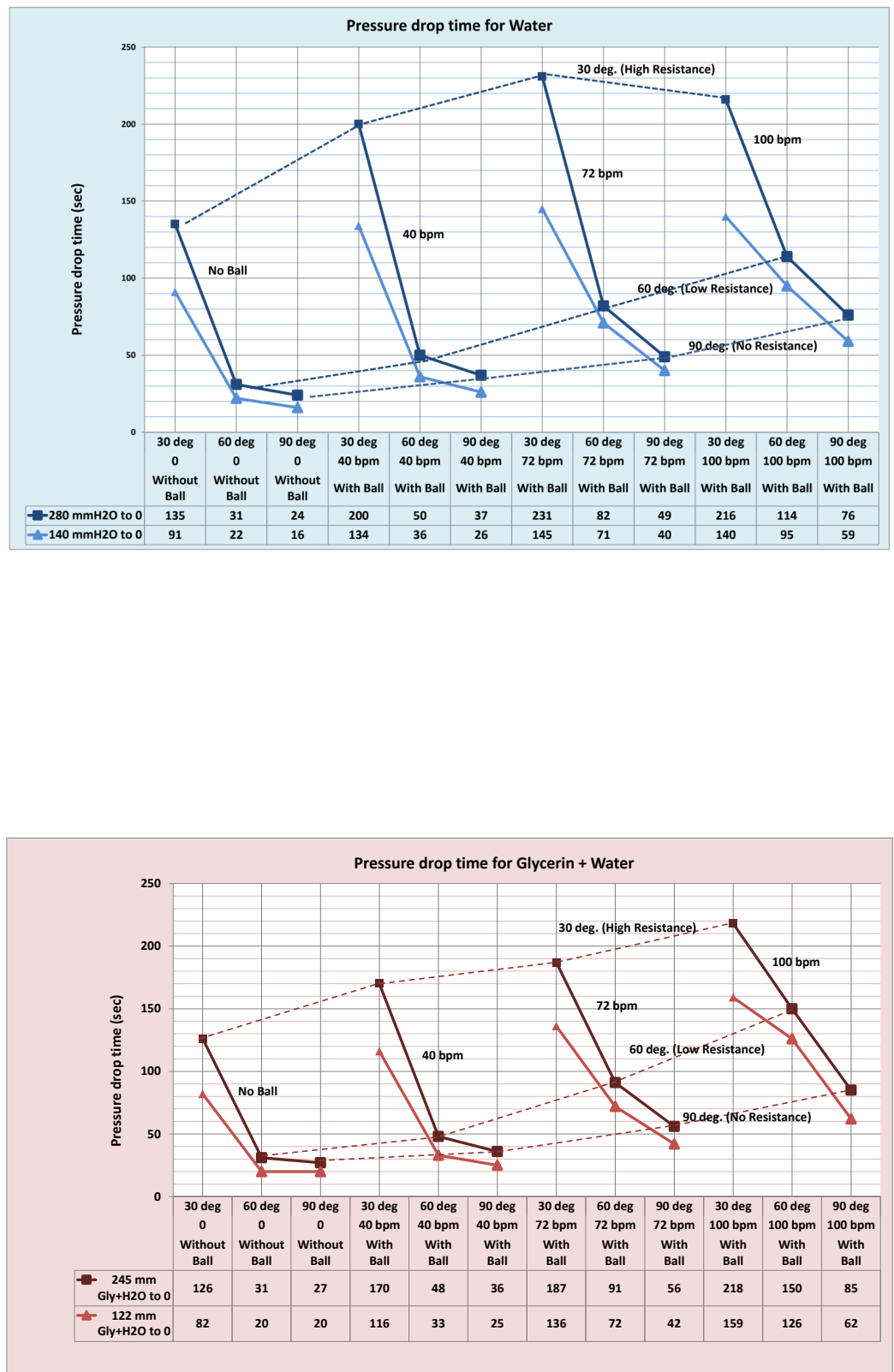


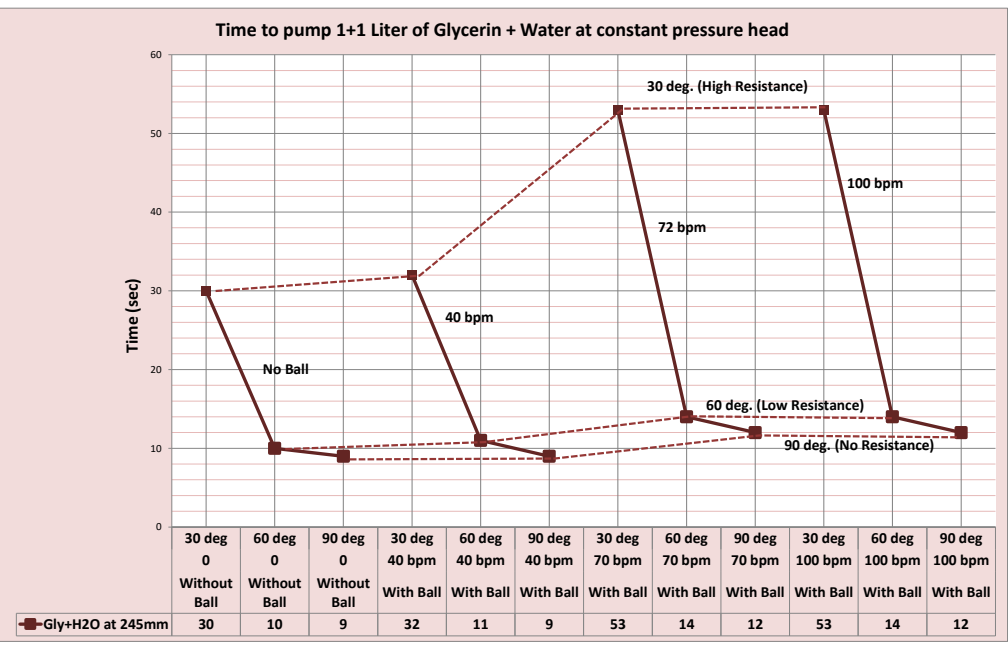

